\title{
Risk Factors of Developing Pneumonia Among Confirmed Measles Cases
}

\author{
Michelle C. Ylade \\ Institute of Child Health and Human Development, National Institutes of Health, University of the Philippines Manila
}

\begin{abstract}
Background. Deaths may occur due to complications of measles. The most common measles complication is pneumonia and accounts for most measles-related deaths.
\end{abstract}

Objective. The study aimed to identify risk factors for developing pneumonia among measles cases.

Methodology. A cross-sectional study was conducted using measles surveillance data from an outbreak in the Philippines from January 2013 to December 2014. Data on age, sex, area of residence, clinical manifestations, receipt of measles vaccine, and other exposure variables were obtained and analyzed using logistic regression.

Results. Approximately 25,166 confirmed measles cases were included in the study where $16 \%$ had pneumonia. Potential risk factors identified in the development of pneumonia among confirmed measles cases were younger age ( $<5$ years = OR 2.49, 95\% Cl: 1.81,3.42; 5-14 years = OR 2.34, 95\% Cl: 1.64,3.33), resident of Mindanao (OR $2.18,95 \% \mathrm{Cl}: 1.74,2.74)$, presence of cough (OR 5.51, 95\% Cl: 2.04,14.86), presence of conjunctivitis (OR 1.31, 95\% $\mathrm{Cl}: 1.11,1.55)$, and being admitted to hospital (OR 3.16, 95\% Cl: 2.57,3.90). Confirmed measles cases with receipt of measles containing vaccine (MCV) $(\mathrm{OR} 0.74,95 \% \mathrm{Cl}: 0.63,0.87)$ were found to be less likely to have pneumonia.

Conclusion. These risk factors help identify cases requiring prompt management to reduce morbidity and mortality in any future measles outbreaks.

Key Words: measles, Philippines, pneumonia

Corresponding author: Michelle C. Ylade, MD, MSc. Institute of Child Health and Human Development Room 112, National Institutes of Health Building, University of the Philippines Manila 623 Pedro Gil Street, Manila, 1000 Philippines Telephone: +632 2545205

Email: mylademd@yahoo.com

\section{INTRODUCTION}

Most measles-related deaths are caused by complications associated with the disease. ${ }^{1,2}$ Complications of measles occur in as many as $40 \%$ of all cases and the risk of complication is increased by extremes of age and underlying conditions including malnutrition. ${ }^{3}$ Pneumonia is the most common fatal complication of measles, occurring in 56 to $86 \%$ of measles-related deaths. Pneumonia has been reported in 2 to $27 \%$ of measles cases among communities in developing countries and in 16 to $77 \%$ of children admitted to hospitals. ${ }^{3}$ Pneumonia occurring in measles cases may be caused by secondary viral or bacterial infections or by the measles virus itself. ${ }^{4}$

The control of measles is centered on vaccination. The World Health Organization (WHO) has established a target in five WHO Regions for measles elimination by 2020 through measles vaccination. ${ }^{5,6}$ Between 2000 and 2013, measles vaccination has decreased measles-related deaths globally by $75 \%$ and it is still considered as the best means of preventing measles. ${ }^{4,7}$ In the Philippines, the case fatality rate for confirmed measles has decreased from $0.51 \%$ 
in 2014 to $0 \%$ in $2016 .{ }^{8,9}$ However in 2017 , case fatality rate among confirmed measles cases was $1.92 \% .{ }^{10}$ Although a safe and cost-effective vaccine has been available for several years, measles remains a major cause of death among young children. ${ }^{7}$

Several studies have explored the risk factors on contracting severe measles. One study identified overcrowding, exposure intensity, prior respiratory infection, and intercurrent infection as factors affecting measles severity. ${ }^{11}$ A retrospective study by Samsi et al showed a model of variable risk factors for developing severe measles involving malnutrition, patient demographic composition, and socio-economic and socio-cultural conditions including availability and utilization of health facilities. The paper also mentioned that the most frequent cause of mortality was the combination of bronchopneumonia-encephalopathy (59.3\%) and bronchopneumonia-encephalopathy-diarrhea (24.1\%) and that most deaths occurred during the first 24 hours of hospitalization. ${ }^{12}$

Literature on risk factors for pneumonia in communitybased studies has been sparse. A prospective study in South India revealed that among 401 cases who had measles complications, 288 had measles-related pneumonia. ${ }^{13} \mathrm{~A}$ hospital-based study in the Philippines noted that the majority of those with measles-related pneumonia were aged less than 24 months. Malnutrition has been found to be associated with the occurrence of measles pneumonia. ${ }^{14}$ The studies on risk factors for the development of pneumonia among measles cases mentioned above were all hospital-based.

A measles outbreak occurred in the Philippines from 2013-2014 affecting the whole country. All measles cases were reported to the Philippine Integrated Disease Surveillance and Response (PIDSR) system through the Epidemiology Bureau of the Department of Health. All suspected measles cases reported to the PIDSR were investigated and specimen collected to confirm measles cases. ${ }^{15}$ This paper provides assessment of risk factors associated with developing pneumonia among confirmed measles cases using routine measles surveillance data.

\section{MATERIALS AND METHODS}

A cross-sectional study of measles-related pneumonia cases compared to measles cases without pneumonia was assessed. Potential risk factors for development of pneumonia among confirmed measles cases based on the January 2013 to 20 December 2014 measles surveillance data from the Department of Health. Characteristics of confirmed measles cases included in the analysis were age, sex, area of residence, receipt of $\mathrm{MCV}$, presence of colds/runny nose, fever, red eye/conjunctivitis, cough, rash, hospital admission, history of travel to an area with known measles transmission, place of probable exposure, and exposure to other measles cases. Confirmed measles cases were defined according to the new classification adapted in 2013. ${ }^{15}$

\section{Case ascertainment}

Cases were defined as individuals classified as measles confirmed in the PIDSR system with a diagnosis of pneumonia during the 2013 to 2014 measles outbreak. Non-cases were defined as measles confirmed cases without pneumonia reported to PIDSR during the same outbreak. All measles confirmed cases were included in the analysis.

\section{Outcome ascertainment}

A confirmed measles case was ascertained to have the outcome if pneumonia was present in the final diagnosis or listed as a complication in the surveillance data.

\section{Statistical analysis}

All statistical analyses were conducted using Stata 13.1. Univariate analysis on all variables was performed to define the characteristics of the study population. A Chi-square test was used to assess the association of each variable to having pneumonia. Logistic regression was used to assess the risk factors for development of pneumonia among measles confirmed cases. Variables whose effect sizes were significant at $\mathrm{p}<0.05$ were included in the final multiple logistic regression model.

\section{RESULTS}

Data were obtained from the Epidemiology Bureau on reported measles cases to the PIDSR from 2013 to 2014. A total of 67,029 suspected measles cases were reported for both years. More than half (52\%) of suspected cases were males and the highest number of suspected measles notifications came from NCR (26\%), Region 4A (16\%) and Region 3 (10\%).

Suspected measles cases were classified according to discarded / non-measles cases; confirmed measles cases; and rubella-confirmed, measles compatible, and pending cases as shown in Figure 1. A total of 25,166 (37\%)

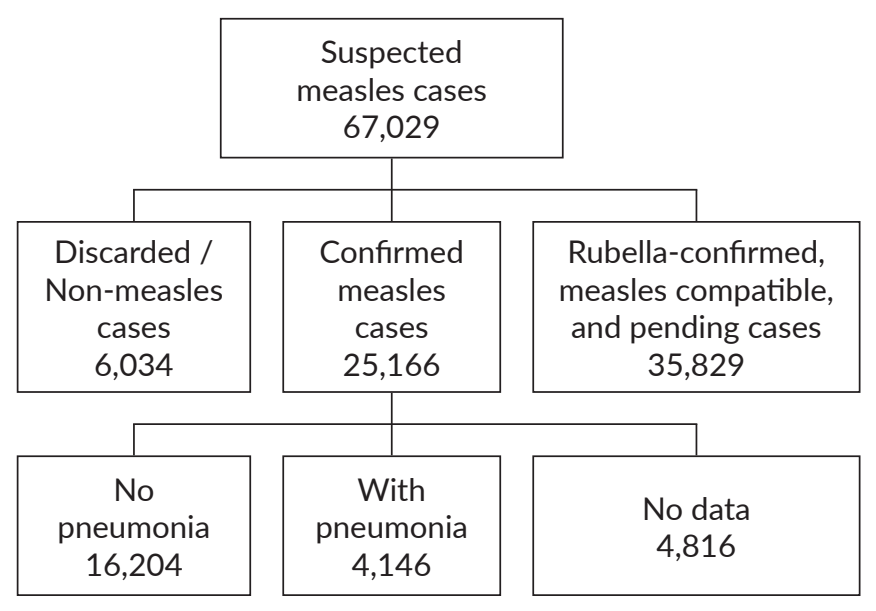

Figure 1. Classification of suspected measles cases and occurrence of pneumonia among confirmed measles cases, Jan 2013 - 20 Dec 2014, Philippines. 
confirmed measles cases were reported to PIDSR. More than half (53\%) of suspected cases were classified as measles compatible, rubella-confirmed, and pending cases while $9 \%$ were classified as discarded/non-measles cases. A total of $4,146(16 \%)$ confirmed measles cases were reported to have pneumonia.

Children aged 1-5 years old had the highest proportion of confirmed measles cases (29\%), followed by children $<1$ year of age at $27 \%$ while those who were aged $16-20$ years old comprised $12 \%$ of confirmed cases (Figure 2). The highest proportion of reported confirmed measles cases were from Region 4A (22\%), NCR (31\%), and Region 3 (12\%) (Table 1).

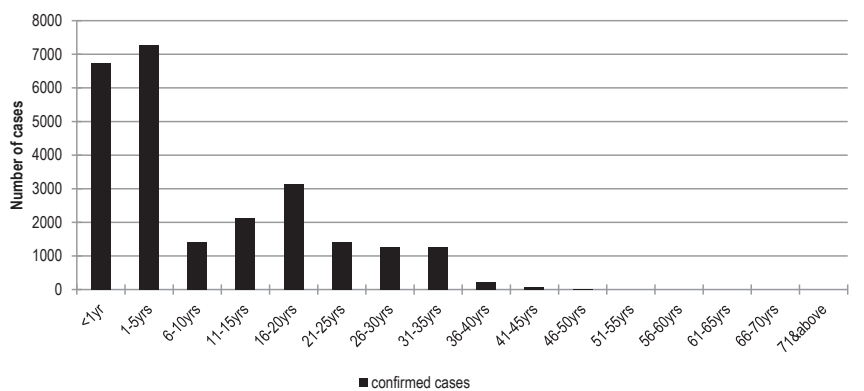

Figure 2. Number of reported confirmed measles cases by age, Jan 2013 to 20 Dec2014, Philippines.

Table 1. Age, sex and area of residence of reported measles cases according to case classification from January 2013 to 20 December 2014, Philippines

\begin{tabular}{|c|c|c|c|c|}
\hline & $\begin{array}{l}\text { Confirmed } \\
\text { Number (\%) }\end{array}$ & $\begin{array}{c}\text { Discarded } \\
\text { Number (\%) }\end{array}$ & $\begin{array}{c}\text { Rubella confirmed/ } \\
\text { Measles compatible } \\
\text { Number (\%) }\end{array}$ & Total (\%) \\
\hline \multicolumn{5}{|l|}{ Age } \\
\hline$<1$ year & $6,733(27)$ & 1,005 (17) & $9,565(27)$ & $17,303(26)$ \\
\hline $1-5$ years & $7,291(29)$ & 1,059 (18) & $9,135(26)$ & $17,485(26)$ \\
\hline 6-10 years & $1,422(6)$ & $513(9)$ & $2,022(6)$ & $3,957(6)$ \\
\hline $11-15$ years & $2,134(8)$ & $615(10)$ & 3,201 (9) & $5,950(9)$ \\
\hline $16-20$ years & $3,135(12)$ & $813(13)$ & $4,711(13)$ & $8,659(13)$ \\
\hline $21-25$ years & $1,404(6)$ & $635(11)$ & $2,399(7)$ & $4,438(7)$ \\
\hline $26-30$ years & $1,271(5)$ & $432(7)$ & $1,953(5)$ & $3,656(5)$ \\
\hline $31-35$ years & $1,251(5)$ & $377(6)$ & $1,879(5)$ & 3,507 (5) \\
\hline $36-40$ years & $234(1)$ & $191(3)$ & 449 (1) & $874(1)$ \\
\hline $41-45$ years & $62(0)$ & $137(2)$ & $142(0)$ & 341 (1) \\
\hline $46-50$ years & $25(0)$ & $70(1)$ & $81(0)$ & $176(0)$ \\
\hline $51-55$ years & $9(0)$ & $56(1)$ & $46(0)$ & $111(0)$ \\
\hline $56-60$ years & $13(0)$ & $40(1)$ & $31(0)$ & $84(0)$ \\
\hline $61-65$ years & $9(0)$ & $34(1)$ & $26(0)$ & $69(0)$ \\
\hline $66-70$ years & $2(0)$ & $11(0)$ & $10(0)$ & $23(0)$ \\
\hline $71 \&$ above & $2(0)$ & $13(0)$ & $8(0)$ & $23(0)$ \\
\hline Missing & $169(1)$ & $33(1)$ & $171(0)$ & $373(1)$ \\
\hline Total & $25,166(100)$ & $6,034(100)$ & $35,829(100)$ & $67,029(100)$ \\
\hline \multicolumn{5}{|l|}{ Sex } \\
\hline Male & $13,340(53)$ & $2,968(49)$ & $18,589(52)$ & $34,897(48)$ \\
\hline Female & $11,826(47)$ & $3,066(51)$ & $17,240(48)$ & $32,132(52)$ \\
\hline Total & $25,166(100)$ & $6,034(100)$ & $35,829(100)$ & $67,029(100)$ \\
\hline \multicolumn{5}{|c|}{ Area of residence (Region) } \\
\hline I & $796(3)$ & $267(4)$ & $1,570(4)$ & $2,633(4)$ \\
\hline II & $620(2)$ & $203(3)$ & $1,415(4)$ & $2,238(3)$ \\
\hline III & $2,939(12)$ & $685(11)$ & $3,408(10)$ & $7,032(10)$ \\
\hline IVA & $5,551(22)$ & $1,066(18)$ & $4,289(12)$ & $10,906(16)$ \\
\hline IVB & $323(1)$ & $210(3)$ & $1,441(4)$ & $1,974(3)$ \\
\hline V & $665(3)$ & $176(3)$ & $1,343(4)$ & $2,184(3)$ \\
\hline VI & $1,046(4)$ & $782(13)$ & $1,457(4)$ & $3,285(5)$ \\
\hline VII & $914(4)$ & $277(5)$ & $1,015(3)$ & $2,206(3)$ \\
\hline VIII & 247 (1) & $62(1)$ & $1,186(3)$ & $1,495(2)$ \\
\hline IX & $241(1)$ & $113(2)$ & $561(2)$ & $915(1)$ \\
\hline$x$ & $740(3)$ & $126(2)$ & $1,633(5)$ & $2,499(4)$ \\
\hline$X I$ & $1,257(5)$ & $337(6)$ & $1,950(5)$ & $3,544(5)$ \\
\hline XII & $857(3)$ & $208(3)$ & $3,192(9)$ & $4,257(6)$ \\
\hline ARMM & $314(1)$ & $45(1)$ & $1,198(3)$ & $1,557(2)$ \\
\hline CAR & 255 (1) & $185(3)$ & 410 (1) & $850(1)$ \\
\hline CARAGA & $592(2)$ & $147(2)$ & $1,192(3)$ & $1,931(3)$ \\
\hline NCR & 7,809 (31) & 1,145 (19) & $8,569(24)$ & $17,523(26)$ \\
\hline Total & $25,166(100)$ & $6,034(100)$ & $35,829(100)$ & $67,029(100)$ \\
\hline
\end{tabular}


Table 2. Comparison of age, sex and area of residence of confirmed measles cases with or without pneumonia, January 2013 to 20 December 2014, Philippines

\begin{tabular}{|c|c|c|c|c|c|}
\hline & $\begin{array}{c}\text { Cases with } \\
\text { pneumonia } \\
\text { Frequency (\%) }\end{array}$ & $\begin{array}{c}\text { Cases without } \\
\text { pneumonia } \\
\text { Frequency (\%) }\end{array}$ & $\begin{array}{c}\text { No data on } \\
\text { pneumonia } \\
\text { Frequency (\%) }\end{array}$ & Total (\%) & p-value ${ }^{1}$ \\
\hline \multicolumn{6}{|l|}{ Age } \\
\hline$<5$ years & $3,052(74)$ & $8,306(51)$ & $2,328(48)$ & $13,686(54)$ & $<0.0001$ \\
\hline $5-14$ years & $435(10)$ & $2,325(14)$ & $696(14)$ & 3,456 (14) & \\
\hline $15-24$ years & $389(9)$ & $3,377(21)$ & $997(21)$ & $4,763(19)$ & \\
\hline 25 years \& above & $257(7)$ & $2,070(13)$ & 754 (16) & $3,081(12)$ & \\
\hline Missing & $13(0)$ & $126(1)$ & $41(1)$ & $180(1)$ & \\
\hline Total & $4,146(100)$ & $16,204(100)$ & $4,816(100)$ & $25,166(100)$ & \\
\hline \multicolumn{6}{|l|}{ Sex } \\
\hline Male & $2,228(54)$ & $8,579(53)$ & $2,533(53)$ & $13,340(47)$ & 0.96 \\
\hline Female & $1,918(46)$ & $7,625(47)$ & $2,283(47)$ & $11,826(53)$ & \\
\hline Total & $4,146(100)$ & $16,204(100)$ & $4,816(100)$ & $25,166(100)$ & \\
\hline \multicolumn{6}{|l|}{ Area of residence } \\
\hline Luzon & $1,783(43)$ & $8,195(51)$ & $1,171(24)$ & $11,149(44)$ & $<0.0001$ \\
\hline Visayas & $328(8)$ & $1,012(6)$ & $867(18)$ & 2,207 (9) & \\
\hline Mindanao & 714 (17) & $1,385(9)$ & $1,902(39)$ & $4,001(16)$ & \\
\hline Metro Manila & $1,321(32)$ & $5,612(35)$ & $876(18)$ & 7809 (31) & \\
\hline Total & $4,146(100)$ & $16,204(100)$ & $4,816(100)$ & $25166(100)$ & \\
\hline
\end{tabular}

${ }^{1}$ Chi-square test

The highest proportion of pneumonia cases were observed among $<5$ years old (74\%). There was little difference in sex but most of pneumonia cases were from Luzon (43\%). The baseline characteristics of measles cases with pneumonia are described in Table 2. Clinical manifestations, vaccination status, hospital admission, history of travel, place of probable exposure, and exposure to probable measles case are presented in Table 3.

Nearly all pneumonia cases had fever, rash and cough. Seventy-three percent of pneumonia cases had conjunctivitis, $84 \%$ had colds and $92 \%$ were admitted in a hospital. Only $20 \%$ of measles related pneumonia cases received measlescontaining vaccine. Most pneumonia cases (60\%) had no history of travel to an area with known measles transmission but $48 \%$ were exposed to other measles cases and exposure probably occurred from the community (45\%).

Sex $(p=0.96)$, fever $(p=0.30)$, rash $(p=0.53)$, colds/runny nose $(p=0.22)$, history of travel to an area with known measles transmission $(\mathrm{p}=0.15)$, and place of probable exposure $(\mathrm{p}=0.19)$ were not associated with having pneumonia. These variables were excluded from multivariate analysis. Variables with evidence of an association with pneumonia included age, area of residence, receipt of any $\mathrm{MCV}$, presence of cough and red eye, hospital admission, and exposure to other confirmed measles case (Table 4).

\section{DISCUSSION}

National measles surveillance data from 2013 to 2014 was analyzed to identify potential risk factors for developing pneumonia among measles cases. In this study, $16 \%$ of confirmed measles cases had pneumonia. Potential risk factors identified were younger age, residence in Mindanao, presence of cough, conjunctivitis, and hospital admission. Receipt of a measles-containing vaccine was found to be protective against developing pneumonia among measles cases.

Age was an important risk factor in the development of pneumonia among measles confirmed cases. Majority of measles cases with pneumonia (74\%) were less than 5 years old. Children in this age group were more likely to develop pneumonia than older children. Malnutrition may play a role in the development of pneumonia by further decreasing the immune response brought by having measles infection. A hospital-based study in Makati, Philippines showed that measles patients with pneumonia were more likely to be marginally underweight compared to those who did not have pneumonia. ${ }^{16}$ However, the study did not mention which particular age group had the most number of marginally underweight children or if nutritional status was measured before or after the diagnosis of pneumonia.

Measles cases living in Mindanao had twice the risk of developing pneumonia compared to those living in Luzon, Visayas and Metro Manila. This can be attributed to the low socio-economic status of the people living in this island. Seven out of the 10 poorest provinces in the Philippines can be found in Mindanao. ${ }^{17}$ Low socio-economic status leads to poor access to health care, lack of maternal education, poor hygiene, and malnutrition.

Among the clinical manifestations of measles, cough and conjunctivitis were found to be associated with developing pneumonia. Measles infection can be acquired through the respiratory tract and occasionally through the conjunctiva. When the virus infects the reticuloendothelial system, secondary viremia occurs where the skin and respiratory tract become infected manifesting the disease. ${ }^{2}$ The presence of cough and conjunctivitis with pneumonia may be due 
Table 3. Clinical characteristics, measles vaccination status and other exposure variables of confirmed measles cases with or without pneumonia, January 2013 to 20 December 2014, Philippines

\begin{tabular}{|c|c|c|c|c|c|}
\hline & $\begin{array}{l}\text { Cases with } \\
\text { pneumonia }\end{array}$ & $\begin{array}{c}\text { Cases without } \\
\text { pneumonia }\end{array}$ & Missing & Total & p-value ${ }^{1}$ \\
\hline \multicolumn{6}{|l|}{ Receipt of any MCV } \\
\hline No & $2,930(71)$ & $7,246(45)$ & $2,025(42)$ & $12,201(48)$ & $<0.0001$ \\
\hline Yes & $849(20)$ & $4,030(25)$ & $865(18)$ & $5,744(23)$ & \\
\hline Missing & $367(9)$ & $4,928(30)$ & $1,926(40)$ & $7,221(29)$ & \\
\hline Total & $4,146(100)$ & $16,204(100)$ & $4,816(100)$ & $25,166(100)$ & \\
\hline \multicolumn{6}{|l|}{ Presence of fever } \\
\hline No & $2(0)$ & $4(0)$ & $0(0)$ & 6 & 0.30 \\
\hline Yes & $4,128(100)$ & $13,756(85)$ & $3,379(70)$ & 2,1263 & \\
\hline Missing & $16(0)$ & $2,444(15)$ & $1,437(30)$ & 3,897 & \\
\hline Total & $4,146(100)$ & $16,204(100)$ & $4,816(100)$ & $25,166(100)$ & \\
\hline \multicolumn{6}{|l|}{ Presence of cough } \\
\hline No & $39(1)$ & $490(3)$ & $124(3)$ & $653(3)$ & $<0.0001$ \\
\hline Yes & $3,982(96)$ & $12,638(78)$ & $3,203(67)$ & $19,823(79)$ & \\
\hline Missing & $125(3)$ & 3,076 (19) & $1,489(31)$ & $4,690(18)$ & \\
\hline Total & $4,146(100)$ & $16,204(100)$ & $4,816(100)$ & $25,166(100)$ & \\
\hline \multicolumn{6}{|l|}{ Presence of rash } \\
\hline No & $0(0)$ & $7(0)$ & $2(0)$ & $9(0)$ & 0.53 \\
\hline Yes & $4,141(100)$ & $15,857(98)$ & 4,755 (99) & $24,753(98)$ & \\
\hline Missing & $5(0)$ & $340(2)$ & $59(1)$ & $404(2)$ & \\
\hline Total & $4,146(100)$ & $16,204(100)$ & $4,816(100)$ & $25,166(100)$ & \\
\hline \multicolumn{6}{|c|}{ Presence of runny nose / colds } \\
\hline No & $483(12)$ & $2,269(14)$ & $591(12)$ & $3,343(13)$ & 0.22 \\
\hline Yes & $3,494(84)$ & $10,596(65)$ & $2,651(55)$ & $16,741(67)$ & \\
\hline Missing & $169(4)$ & $3,339(21)$ & $1,574(33)$ & $5,082(20)$ & \\
\hline Total & $4,146(100)$ & $16,204(100)$ & $4,816(100)$ & $25,166(100)$ & \\
\hline \multicolumn{6}{|c|}{ Presence of red eye / conjunctivitis } \\
\hline No & $923(22)$ & $3,670(23)$ & $874(18)$ & $5,467(22)$ & 0.003 \\
\hline Yes & $3,021(73)$ & $9,053(56)$ & $2,314(48)$ & $14,388(57)$ & \\
\hline Missing & $202(5)$ & $3,481(21)$ & $1,628(34)$ & $5,311(21)$ & \\
\hline Total & $4,146(100)$ & $16,204(100)$ & $4,816(100)$ & $25,166(100)$ & \\
\hline \multicolumn{6}{|l|}{ Hospital admission } \\
\hline No & $337(8)$ & $5,330(33)$ & $854(18)$ & $6,521(26)$ & $<0.0001$ \\
\hline Yes & $3,808(92)$ & $8,955(55)$ & $2,564(53)$ & $15,327(61)$ & \\
\hline Missing & $1(0)$ & $1,919(12)$ & $1,398(29)$ & $3,318(13)$ & \\
\hline Total & $4,146(100)$ & $16,204(100)$ & $4,816(100)$ & $25,166(100)$ & \\
\hline \multicolumn{6}{|l|}{ History of travel } \\
\hline No & $2,496(60)$ & $6,622(41)$ & $2,136(44)$ & $11,254(45)$ & 0.15 \\
\hline Yes & $685(17)$ & $1,926(12)$ & $433(9)$ & $3,044(12)$ & \\
\hline Missing & $965(23)$ & $7,656(47)$ & $2,247(47)$ & $10,868(43)$ & \\
\hline Total & $4,146(100)$ & $16,204(100)$ & $4,816(100)$ & $25,166(100)$ & \\
\hline \multicolumn{6}{|c|}{ Place of probable exposure } \\
\hline Daycare/school & $71(2)$ & $423(3)$ & $94(2)$ & $588(2)$ & 0.19 \\
\hline Health center facility & $139(3)$ & $351(2)$ & $85(2)$ & $575(2)$ & \\
\hline Home/dormitory & $857(21)$ & $2,581(16)$ & $727(15)$ & 4,165 (17) & \\
\hline Community & $1,860(45)$ & $4,816(30)$ & $1,300(27)$ & $7,976(32)$ & \\
\hline Missing & $1,219(29)$ & $8,033(50)$ & $2,610(54)$ & $11,862(47)$ & \\
\hline Total & $4,146(100)$ & $16,204(100)$ & $4,816(100)$ & $25,166(100)$ & \\
\hline \multicolumn{6}{|c|}{ Exposure to other measles case } \\
\hline No & $1,031(25)$ & $3,617(22)$ & $1,004(21)$ & $5,652(22)$ & 0.034 \\
\hline Yes & $1,983(48)$ & $4,931(30)$ & $1,219(25)$ & $8,133(32)$ & \\
\hline Missing & $1,132(27)$ & $7,656(47)$ & $2,593(54)$ & $11,381(45)$ & \\
\hline Total & $4,146(100)$ & $16,204(100)$ & $4,816(100)$ & $25,166(100)$ & \\
\hline
\end{tabular}

${ }^{1}$ Chi-square test

to immune suppression caused by measles infection and/ or malnutrition with probable secondary viral or bacterial co-infection. ${ }^{1}$ Hospital admission was also identified as associated with pneumonia among confirmed measles cases. This association may be because sicker children were more likely to be hospitalized i.e.: due to reverse causation. 
Table 4. Crude and adjusted odds ratio of identified risk factors for developing pneumonia among confirmed measles cases

\begin{tabular}{|c|c|c|c|c|c|}
\hline & $\begin{array}{l}\text { Crude OR }{ }^{1} \\
\left(95 \% \mathrm{Cl}^{2}\right)\end{array}$ & p-value ${ }^{3}$ & $\begin{array}{c}\text { Adjusted OR }{ }^{1} \\
\left(95 \% \mathrm{Cl}^{2}\right)\end{array}$ & p-value ${ }^{3}$ & p-value ${ }^{4}$ \\
\hline \multicolumn{6}{|l|}{ Age } \\
\hline$<5 y r s$ & $2.38(1.84-3.07)$ & $<0.0001$ & $2.49(1.81-3.42)$ & $<0.0001$ & $<0.0001$ \\
\hline $5-14$ yrs & $1.97(1.47-2.65)$ & $<0.0001$ & $2.34(1.64-3.33)$ & $<0.0001$ & \\
\hline $15-24$ yrs & $0.80(0.58-1.11)$ & 0.19 & $0.97(0.66-1.42)$ & 0.865 & \\
\hline $25 \&$ above & 1 & & 1 & & \\
\hline \multicolumn{6}{|l|}{ Area of residence } \\
\hline Metro Manila & 1 & & 1 & & $<0.0001$ \\
\hline Luzon & $1.63(1.40-1.90)$ & $<0.0001$ & $1.47(1.23-1.75)$ & 0.0001 & \\
\hline Visayas & $1.56(1.17-2.07)$ & 0.002 & $1.3(0.96-1.77)$ & 0.092 & \\
\hline Mindanao & $3.09(2.52-3.79)$ & $<0.0001$ & $2.18(1.74-2.74)$ & 0.0001 & \\
\hline \multicolumn{6}{|c|}{ Receipt of any MCV } \\
\hline No & 1 & & 1 & & \\
\hline Yes & $0.64(0.55-0.75)$ & $<0.0001$ & $0.74(0.63-0.87)$ & $<0.0001$ & $<0.0001$ \\
\hline \multicolumn{6}{|l|}{ Cough } \\
\hline No & 1 & & 1 & & \\
\hline Yes & $5.87(2.62-13.17)$ & $<0.0001$ & $5.51(2.04-14.86)$ & 0.001 & $<0.0001$ \\
\hline \multicolumn{6}{|c|}{ Red eye / Conjunctivitis } \\
\hline No & 1 & & 1 & & \\
\hline Yes & $1.26(1.08-1.47)$ & 0.003 & $1.31(1.11-1.55)$ & 0.02 & $<0.0001$ \\
\hline \multicolumn{6}{|c|}{ Hospital admission } \\
\hline No & 1 & & 1 & & \\
\hline Yes & $3.47(2.88-4.18)$ & $<0.0001$ & $3.16(2.57-3.90)$ & $<0.0001$ & $<0.0001$ \\
\hline \multicolumn{6}{|c|}{ Exposure to other measles case } \\
\hline No & 1 & & & & \\
\hline Yes & $1.17(1.01-1.36)$ & 0.035 & & & \\
\hline
\end{tabular}

${ }^{1}$ Odds ratio. ${ }^{2}$ Confidence interval. ${ }^{3}$ Wald's test. ${ }^{4}$ Likelihood ratio test

Measles cases who received measles-containing vaccine were less likely to have pneumonia (OR: $0.74,95 \% \mathrm{CI}$ : $0.63-0.87)$. It has been shown that vaccinated children who develop measles have a much lower rate of complications than unvaccinated children. ${ }^{2} \mathrm{~A}$ study in Brazil on risk factors for childhood pneumonia showed that measles vaccine was associated with a $21 \%$ reduction in the risk of developing pneumonia even among non-measles cases. ${ }^{18}$

Pneumonia is the most common complication of measles and causes most measles-related deaths. Identification of risk factors for developing pneumonia among measles cases is important for prompt identification and management. Vaccination with a measles containing vaccine helps prevent measles and its complications.

\section{CONCLUSIONS}

Measles associated pneumonia has been a complication and a major cause of death during the 2013 outbreak in the Philippines and was noted among very young children and in regions where poverty was more prevalent like in Mindanao. Other risk factors identified for the development of pneumonia among measles cases were presence of cough, red eye, and hospital admission. Measles cases who received MCV were less likely to develop pneumonia. These risk factors can help identify cases requiring prompt management to reduce morbidity and mortality in any future outbreaks.

\section{Acknowledgments}

I would like to thank the Department of Health for sharing their measles surveillance data. I am grateful for the academic support given by my supervisors, Dr. Paul Fine and Dr. Punam Mangtani, at the London School of Hygiene and Tropical Medicine. Lastly, I would like to acknowledge my supervisor, Dr. Anna Lena Lopez, colleagues at the Institute of Child Health and Human Development, and my family and friends for the encouragement and support during the writing of this paper.

\section{Statement of Authorship}

The author has approved the final version submitted.

\section{Author Disclosure}

The author has declared no conflict of interest.

\section{Funding Source}

No external funding.

\section{REFERENCES}

1. Perry RT, Halsey NA. The clinical significance of measles: a review. J Infect Dis. 2004;189 Suppl 1:S4-16. Epub 2004/04/24. doi: $10.1086 / 377712$.

2. Duke T, Mgone CS. Measles: not just another viral exanthem. The Lancet. 2003;361(9359):763-73. Epub 2003/03/07. doi: 10.1016/ s0140-6736(03)12661-x.

3. SA P,WA O, PA O. Vaccines. 6th Edition ed: Elsevier Saunders; 2013. 
4. Moss WJ. Measles. Lancet. 2017 ;390(10111):2490-2502. doi: 10.1016/S0140-6736(17)31463-0. Epub 2017 Jun 30. Review.

5. Durrheim DN, Crowcroft NS, Strebel PM.Measles - The epidemiology of elimination. Vaccine. 2014 5;32(51):6880-6883. doi: 10.1016/j. vaccine.2014.10.061. Epub 2014 Nov 4.

6. Measles elimination field guide: World Health Organization Western Pacific Region; 2013.

7. Measles: World Health Organization [Online]; [cited 2015 June]. Available from: http://www.who.int/mediacentre/factsheets/fs286/en/.

8. Measles Rubella Cases Monthly Report. Measles Rubella Cases Monthly Report [Online]. January 1-August 27, 2016; (Morbidity Week 34). [cited 2017 October]. Available from: http://www.doh.gov. $\mathrm{ph} /$ sites/default/files/statistics/MEASLES-RUBELLA_MW34.pdf.

9. Measles Rubella Bulletin Morbidity Week 9Mar 1-7, 2015. [Online]; [cited 2015 June]. Available from: http://www.doh.gov.ph/sites/ default/files/statistics/measles9.pdf.

10. Measles Rubella Cases. Department of Health Epidemiology Bureau Public Health Surveillance Division; January 1 - September 2, 2017.

11. Nieburg P, Dibley MJ. Risk factors for fatal measles infections. Int J Epidemiol. 1986;15(3):309-11. Epub 1986/09/01.
12. Samsi TK, Ruspandji T, Susanto I, Gunawan K. Risk factors for severe measles. Southeast Asian J Trop Med Public Health. 1992;23(3):497503. Epub 1992/09/01.

13. Guidelines on verification of measles elimination in the Western Pacific Region. World Health Organization Western Pacific Region; 2013.

14. Enriquez M. Risk Factors Associated with Measles. PIDSP Journal. 2004;8(1).

15. Manual of Procedures for the Philippine Integrated Disease Surveillance and Response. In: Center NE, editor. 3rd ed. Philippines: Department of Health; 2014.

16. Mortel N, Alcaneses M. Factors predictive of pneumonia in measles. Makati Medical Center Proceedings. 2000;9:16-20.

17. Herrera M, Roman F, Alarilla M. Overview of Health Sector Reform in the Philippines and Possible Opportunities For Public-Private Partnerships. Asian Institute of Management.

18. Fonseca W, Kirkwood BR, Victora CG, Fuchs SR, Flores JA, Misago C. Risk factors for childhood pneumonia among the urban poor in Fortaleza, Brazil: a case-control study. Bull World Health Organ. 1996;74(2):199-208. 